\title{
Sandredt.
}

Sn zwei Theilen ober vier Bänben.

\section{Dritter Band.}





\section{Âlfgemeine \\ $\mathfrak{Z} \mathfrak{a} \mathfrak{n} \mathfrak{d} \mathfrak{x} \mathfrak{d} \mathfrak{t}$ \\ für bie \\ Preukiifdert Stanten.}

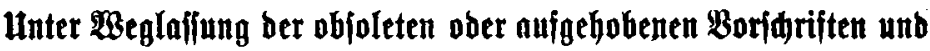

Einjdaltung ber jiingeren nodj geltenben Beitimumungen,

beraubgegeben

mit

fiommentar $\mathfrak{i n}$ Anmerkungen

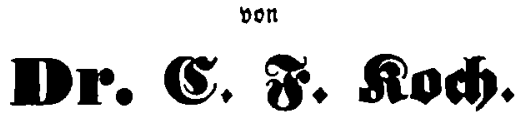

Wit Bewligigung ber gerren 4 . 2aud unb comp.

Bwriter Cheil, exfet yand.

Berlin, 1854 .

3. Gutttentag.

(․ Tra $\mathfrak{x}$ twein'fder $\mathfrak{B} \mathfrak{u}$ querlag.) 
